\title{
Radiology Beyond Digital
}

\author{
Miguel Souto Bayarri* \\ Professor of Radiology, University of Santiago de Compostela, Spain \\ *Corresponding author: Miguel Souto Bayarri, Professor of Radiology, University of Santiago de Compostela, Spain
}

\begin{tabular}{|c|c|}
\hline ARTICLE INFO & ABSTRACT \\
\hline Received: 幽 March 11, 2020 & Citation: Miguel Souto Bayarri. Radiology Beyond Digital. Biomed J Sci \& Tech Res 26(4)- \\
\hline Published: 蔧 March 26, 2020 & 2020. BJSTR. MS.ID.004396. \\
\hline
\end{tabular}

Published: March 26, 2020

2020. BJSTR. MS.ID.004396.

\section{Short Communication}

Thirty years ago, there was not the certainty that the organization of our health systems was headed for the digital revolution; it was something that was blowing in the wind. Recently, it is well known that there have been great changes. One of the key points of the digital to analog transformation has to do with the communication and the transmission of messages. We have gone from the primacy of the words to that of the images, because the irruption of the exact digital images against those full of artifacts of analog techniques. Of importance, we must also confront the hypothesis of progressively aging societies in the coming decades. As a result, what are the main surprises that will come to us from technology in the coming years? It is impossible to know. But I venture to point out three innovations with character, and potentially transformative. One is in the field of archiving and communications, where there will be interesting news related to storage and also to the improvement in the speed of transmission and recovery of images, as well as technologies at lower costs. The second is the increasing interconnection of all types of devices and objects through the Network. Medical reports can be written in a support (tablet, telephone...) that will not necessarily have to be located in either a hospital or other health center. A third group of innovations will be related to technologies that may improve diagnosis and treatment, either by lowering the price of medical services themselves, by helping people with disabilities, by improving the quality of life of the elderly, or by developing algorithms for computer-aided diagnosis.

This would be the moment to promote a technology guided by social justice, and whose benefits reach everyone. It is time to give political content to technology. It is the time to privilege research to address major social problems by building a socially useful technology. Some of these advances, already halfway between legend and reality, will be listened with interest by many professionals, but with disinterest on the part of others, perhaps afraid by the unprecedented role of the computer in the medical diagnosis. That this, soon become reality will depend, also, on the public and private research and financial effort that is put to the service of this objective. The importance of basic and applied research must always be remembered. And also, of the fundamental role that the universities and the companies must play in that field. The scientific system and the universities should be a basic pillar on which this whole process should be based. The capacity of the scientific and technological innovation of a society depends on a very important way of the university. It is pertinent to remember that university and research centers have generated many of the products that companies have subsequently transformed into wealthy inventions that have profoundly marked the current society, such as X-rays and CT scanning. The fact is that in many countries, such as Spain, whose technological or scientific-technical system is traditionally weak, the focus has never been on the transfer to the industry of research and innovation developed in the universities. In fact, that would be one of the endemic ills of our University, its true Achilles heel, the lack of relationship with the industry [1].

The results of the research must serve the country's prosperity, for which R \& D should not be confined to laboratories. In this context, drastically reducing the R \& D budget is to opt for a particular model of productive specialization. Today, all data shows that a model is being chosen in which the priority is not to build an 
enlightened and modern community by creating a robust research with the capacity to create knowledge. Under these conditions it is not surprising that everything is reduced to elite research groups with a publishing curriculum but divorced from society and useless to produce the transformations that are needed. To conclude: the world we inhabit is full of surprises and secrets and immersed in a process of changes whose scope we still do not imagine. We live a time of important dichotomies: the analog being trying to locate itself in a digital world. The digital revolution that took place in the last decades, also in hospitals, triggered a series of irreversible consequences. But it also clearly consolidated a fact of even greater dimensions: technology and digitalization began to grow and to occupy more space every day in the departments and specialized journals, and they came to dominate definitively the diagnostic imaging. Because of this fast and continuous way of research, the techniques of diagnostic imaging are today "mestizo" products in which the principles of radiology and computer science have shown that both R \& D earthquakes could be fused and supplemented to give a prestigious image of science [2].

Today, the idea matrix and motor of the synergy between the two subjects "computer and diagnosis" is still, that there is only one responsible for the diagnosis: the doctor. But we could transmit here a part of the legend. The fact that two of the most emergent technologies of the late twentieth century, the computer technology pioneered by Turing and von Neumann and the imaging technology pioneered by Roentgen and Hounsfield, have followed confluent paths, it could permit to see in the horizon a new coordinated action: that of medical imaging with artificial intelligence. This will affect the computerized diagnostic process in such a way, that makes it impossible to predict how far it can go. In any case, it should be clear that these are tools that will enrich the radiologist's work, because, at least for now, there is no CAD - AI capable of replacing the doctor's criteria. Expectation is therefore, and however, justified.

\section{References}

1. Souto M, Malagari K, Tucker D, Tahoces PG, Correa J, et al. (1994) Digital Radiography of the Chest. State of the Art. European Radiology 4: 281297.

2. Suárez J, Tilve A, López R, Ferro G, Quiles J, et al. (2017) Integrating CAD modules in a PACS environment using a wide computing infrastructure. International Journal CARS 12(4): 657-667.
ISSN: 2574-1241

DOI: $10.26717 /$ BJSTR.2020.26.004396

Miguel Souto Bayarri. Biomed J Sci \& Tech Res

(C) (P) This work is licensed under Creative Submission Link: https://biomedres.us/submit-manuscript.php Commons Attribution 4.0 License



